\title{
Evaluating the Inclusion of Cold-Pressed Rapeseed Cake in the Concentrate for Dairy Cows upon Ruminal Biohydrogenation Process, Ruminal Microbial Community and Milk Production and Acceptability
}

\author{
Idoia Goiri (D), Izaro Zubiria, Jose Luís Lavín, Hanen Benhissi, Raquel Atxaerandio (D), Roberto Ruiz, \\ Nerea Mandaluniz and Aser García-Rodríguez *D
}

check for

updates

Citation: Goiri, I.; Zubiria, I.; Lavín, J.L.; Benhissi, H.; Atxaerandio, R.; Ruiz, R.; Mandaluniz, N.;

García-Rodríguez, A. Evaluating the Inclusion of Cold-Pressed Rapeseed Cake in the Concentrate for Dairy Cows upon Ruminal Biohydrogenation Process, Ruminal Microbial Community and Milk Production and Acceptability. Animals 2021, 11, 2553. https:// doi.org/10.3390/ani11092553

Academic Editors: Einar

Vargas-Bello Perez, Heidi Leskinen and Margalida Joy

Received: 3 June 2021

Accepted: 27 August 2021

Published: 30 August 2021

Publisher's Note: MDPI stays neutral with regard to jurisdictional claims in published maps and institutional affiliations.

Copyright: (c) 2021 by the authors. Licensee MDPI, Basel, Switzerland. This article is an open access article distributed under the terms and conditions of the Creative Commons Attribution (CC BY) license (https:// creativecommons.org/licenses/by/ $4.0 /)$.
Campus Agroalimentario de Arkaute s/n, NEIKER-Basque Institute for Agricultural Research and Development, Basque Research and Technology Alliance (BRTA), 01192 Vitoria-Gasteiz, Spain; igoiri@neiker.eus (I.G.); izaro23@hotmail.com (I.Z.); jllavin@neiker.eus (J.L.L.); hanening@gmail.com (H.B.); ratxaerandio@neiker.eus (R.A.); rruiz@neiker.eus (R.R.); nmandaluniz@neiker.eus (N.M.)

* Correspondence: aserg@neiker.eus; Tel.: +34-945-121-313

Simple Summary: Soybean meal and palm oil are important protein and energy sources in European livestock production, respectively. In the next decades, the demand for these feedstuffs is supposed to increase as the world population and its demand for meat and dairy products increases. Alternatives to replace those feedstuffs are necessary. It is necessary to promote low-input, local, and circular production systems: in this sense, adopting feeding systems that use cheaper and local alternative feedstuffs represents a good strategy. One of them is the product obtained after a simple pressing process for the production of biofuels. Cold pressing usually produces oil that can be used as biofuel and a cake rich in fat and with high oil quality but with lower protein content than the conventionally solvent-extracted cakes. Therefore, the availability of cold-pressed cakes can represent an example of integration between the industry and livestock production. The objective of this study was to assess the suitability of formulating cold-pressed rapeseed cake (CPRC) in a dairy cows' concentrate as a substitute for conventional feedstuffs. Feeding CPRC has the advantage of slightly improving the milk fatty acid profile and consumer acceptance. In conclusion, CPRC can replace conventional feedstuffs without detrimental effects on milk production and composition.

Abstract: The aim of this trial was to assess the effect of feeding a concentrate including cold-pressed rapeseed cake (CPRC) on productive performance, milk quality and its sensory properties, ruminal biohydrogenation, and bacterial communities. Eighteen cows were paired, and two experimental diets (control vs. CPRC) were distributed within the pair. Concentrates were iso-energetic and iso-proteic and contained similar amounts of fat. The average days in milk, milk yield, and body weight of the animals were (mean \pm SD) $172 \pm 112 \mathrm{~d}, 585 \pm 26 \mathrm{~kg}$, and $25.4 \pm 6.2 \mathrm{~kg} / \mathrm{d}$, respectively. The experiment lasted for $10 \mathrm{wk}$. Feeding CPRC resulted in lower ruminal saturated $(p<0.001)$ and higher monounsaturated ( $p=0.002)$ fatty acids. Feeding CPRC increased Ruminococcus, Prevotella, and Entodinium but decreased Blautia; $p$-75-a5; undefined genera within orders Clostridiaceae and RF39 and within families Christensenellaceae, Lachnospiracease, and Ruminococcaceae; and fungi from the phylum neocallimastigomycota. The milk fatty acid profile was characterized by a lower n6:n3 ratio $(p=0.028)$. Feeding CPRC did not affect the milk yield, milk quality, or fat corrected milk $(p>0.05)$. Feeding CPRC improved the overall milk acceptability $(p=0.047)$. In conclusion, CPRC affected some microbial taxa, modified the biohydrogenation process, and improved the milk fatty acid profile and consumer acceptance without detrimental effects on milk production and composition.

Keywords: oilseed; alternative feedstuffs; palm oil; soybean meal; dairy cattle 


\section{Introduction}

Soybean meal and palm oil are important protein and energy input sources in European livestock production. In the next decades, the demand for these feedstuffs is supposed to increase as the world population and its demand for meat and dairy products increases [1]. The creation of massive plantations to produce either soybean meal [2] or palm oil [3] means that wild forests have been replaced with monocultures. Burning of forests to make space for soybean or palm also has social and environmental impacts [2]. Deforestation removes the local economy of these regions, reduces biodiversity, and pollutes the environment, being recognized as a major contributor to the emission of greenhouse gases [2]. In addition, the impact of the transportation of these feedstuffs from their origin has to be kept in mind in the context of the actual need for more sustainable farming systems.

The EU has been supporting farmers to adopt or maintain practices that contribute to fulfill environmental and climate goals through the "green direct payment" (or "greening"), which rewarded, among others, crop diversification. This policy is expected to continue through the agricultural practices included in the eco-schemes of the new CAP reform. In recent decades in Europe, this fact has led to an increase in landing of different oilseeds, such as sunflower or rapeseed. In this context of increased oilseed landing, alternative uses have been proposed. One example has been a simple pressing process for the production of biofuels in local areas using cold-pressing. Cold presses are normally mechanically operated and often involve a screw device that is tightened against the paste to extract the oils. In this process, therefore, neither solvents nor heat are applied to help in the extraction. This process usually produces oil that can be used as biofuel and a cake rich in fat and with high oil quality but with lower protein content than the conventionally solvent-extracted cakes. As a consequence, an innovative local agricultural production chain based on the cultivation of oilseeds has been developed. Livestock production systems in the same area require protein and energy supplements from the market. Therefore, the availability of cold-pressed cakes can represent an example of integration between the industry and local livestock production.

Feeding studies with cold-pressed rapeseed cake (CPRC) have shown that its use as a lipid supplement in ruminant diet is susceptible to reducing the extent of ruminal biohydrogenation $(\mathrm{BH})$ and to modifying the ruminal fatty acid (FA) profile towards reduced saturated FA content and increased mono- and polyunsaturated FA levels, as was documented in meat [4], dairy sheep milk [5,6], and cheese [7]. These changes occur with no detrimental effect on the rumen in vitro fermentation process $[8,9]$, apparent digestibility [10], or productive performance [5,6], presenting this cake as a very promising alternative to soybean cake and palm oil. However, there is a lack of studies covering the potential use of CPRC on dairy cow diets' and its effect on milk production and quality.

The effect of dietary lipids on nutrients degradability and digestibility as well as on animal products FA profile is well known. These relationships are mainly mediated by the toxicity of unsaturated fatty acid (UFA) on many microorganisms, especially fibrolytic bacteria [11]. Nevertheless, no recent studies have elucidated the specific effect of CPRC, rich in UFA, on ruminal populations so far. To better understand how CPRC affects the ruminal ecosystem, sequencing methods are promising to be implemented, offering detailed information about the microbial complexity and functionality.

Therefore, in the present study, we used locally produced oil-rich CPRC in the formulation of a concentrate for dairy cows and we hypothesize that the oil present in this cake, rich in UFA, could modify the ruminal microbial communities and therefore ruminal biohydrogenation process, leading to a shift in milk FA profile towards an improved n3:n6 ratio. Moreover, we also expect a change in milk sensory characteristics due to the expected more unsaturated milk FA profile [12]. For this reason, the objective of the current trial was to assess the effect of feeding a concentrate including CPRC on productive performance, milk composition and its sensory properties, ruminal biohydrogentation process, and bacterial communities. 


\section{Materials and Methods}

\subsection{Animals and Treatments}

The trial was conducted at the experimental research farm of Fraisoro Farm School (Zizurkil, Spain). Cows were in loose housing conditions. A total of 18 cows were used; 10 Holstein (H) and 8 Brown Swiss (BS). The average days in milk (DIM), body weight (BW), number of parity, and milk yield of the cows before starting the experiment were $($ mean \pm SD) $172 \pm 112 \mathrm{~d}, 585 \pm 26 \mathrm{~kg}, 1.9 \pm 1.1$, and $25.4 \pm 6.2 \mathrm{~kg} / \mathrm{d}$, respectively. Animals were paired by taking into account the breed, number of parity, DIM, and mean milk yield during a 2-week covariate period. At the end of the covariate period, cows were randomly assigned (within pair) to the CTR or CPRC concentrate for the experimental trial. Concentrates were fed for $10 \mathrm{wk}$; the first $2 \mathrm{wk}$ were for adaptation to the diets, and during the last $8 \mathrm{wk}$, measurements were taken. Concentrates were formulated to be iso-proteic and iso-energetic and to provide similar amounts of fat, following the NRC [13] recommendations (Table 1). Table 2 shows the FA profile of the two experimental concentrates. Cows within a pair received the same quantity of concentrate $(7 \pm 1.3 \mathrm{~kg} / \mathrm{d})$, but they had ad libitum access to a basal forage ration. Concentrate was offered in individual buckets three times per day.

Table 1. Ingredients and chemical composition of basal forage ration and experimental concentrates (CTR, CPRC).

\begin{tabular}{|c|c|c|c|}
\hline \multirow[t]{2}{*}{ Item } & \multicolumn{3}{|c|}{ Experimental Concentrates } \\
\hline & CTR & CPRC & $\begin{array}{c}\text { Basal } \\
\text { Forage }\end{array}$ \\
\hline \multicolumn{4}{|l|}{ Ingredients composition (g/kg DM) } \\
\hline Corn & 225 & 156 & \\
\hline Soybean meal & 210 & 148 & \\
\hline Cold-pressed rapeseed cake & 0 & 234 & \\
\hline Palm Kernel meal & 167 & 0 & \\
\hline Distillers dried grains & 139 & 18 & \\
\hline Barley & 108 & 236 & \\
\hline Wheat & 55 & 150 & \\
\hline Molasses & 20 & 20 & \\
\hline Hydrogenated palm fat & 20 & 0 & \\
\hline Alfalfa pellets & 20 & 0 & \\
\hline Minerals and vitamins ${ }^{1}$ & 36 & 38 & \\
\hline Maize silage & & & 295 \\
\hline Grass silage & & & 615 \\
\hline Barley straw & & & 90 \\
\hline \multicolumn{4}{|l|}{ Chemical composition (g/kg DM) } \\
\hline Dry matter & 883 & 885 & 467 \\
\hline Starch & 290 & 310 & 61 \\
\hline Crude protein & 190 & 190 & 121 \\
\hline Neutral detergent fibre & 205 & 185 & 405 \\
\hline Acid detergent fibre & 90 & 92 & 315 \\
\hline Acid detergent lignin & 23 & 20 & 41 \\
\hline Ether extract & 60 & 63 & 22 \\
\hline Net energy content (UFL) & 1 & 1 & \\
\hline
\end{tabular}


Table 2. Fatty acid composition of experimental concentrates.

\begin{tabular}{|c|c|c|}
\hline Key Fatty Acids (g/100 g of Total Fatty Acids) & CTR & CPRC \\
\hline $\mathrm{C} 12: 0$ & 7.61 & 0.090 \\
\hline C13:0 & 0.030 & 0.010 \\
\hline $\mathrm{C} 14: 0$ & 3.19 & 0.280 \\
\hline C150 & 0.040 & 0.100 \\
\hline $\mathrm{C} 16: 0$ & 23.7 & 10.4 \\
\hline C17:0 & 0.080 & 0.070 \\
\hline C18:0 & 2.90 & 1.82 \\
\hline C20:0 & 0.230 & 0.470 \\
\hline $\mathrm{C} 22: 0$ & 0.150 & 0.310 \\
\hline C23:0 & 0.060 & 0.060 \\
\hline C24:0 & 0.270 & 0.240 \\
\hline C16:1 cis-9 & 0.120 & 0.270 \\
\hline C18:1 cis-9 & 23.4 & 41.0 \\
\hline C18:1 cis-11 & 1.13 & 4.47 \\
\hline C20:1 cis-11 & 0.220 & 0.840 \\
\hline C18:2 cis- 9 cis- 12 & 35.0 & 32.7 \\
\hline C18:3 cis- 9 cis- 12 cis- 15 & 1.63 & 6.30 \\
\hline
\end{tabular}

CTR: control; CPRC: cold-pressed rapeseed cake.

Cows were milked with an automatic milking system (AMS, DeLaval, 2004) machine with free access to the AMS for $22.5 \mathrm{~h} / \mathrm{d}$ ( $1.5 \mathrm{~h}$ for cleaning of the system). Milking intervals were set to a minimum of $6 \mathrm{~h}$ from the previous milking. Nevertheless, if a milking failure occurred, cows would be granted permission to be milked again immediately. During the day, for any particular cow, when the time passed since last milking was more than $12 \mathrm{~h}$, the cow would be forced to visit the AMS.

\subsection{Sampling and Measurements}

Daily milk production was recorded individually at each milking by the AMS. On the last day of the covariate period and during weeks $2,4,6,8$, and 10 of the experimental period, milk samples were taken from the AMS at each milking and stored with azidiol $(3.3 \mathrm{~mL} / \mathrm{L})$ at $4{ }^{\circ} \mathrm{C}$ for fat, protein, and lactose determination (ILL, Lekunberri, Spain). Additional milk samples were taken at each milking on weeks 4 and 9. Then, these milk samples were bulked by animal and day on a milk production basis and were stored at $-20 \pm 5{ }^{\circ} \mathrm{C}$ with azidiol $(3.3 \mathrm{~mL} / \mathrm{L}$ ) for FA composition analysis (LIGAL, Mabegondo, Spain). Offered basal forage and orts were sampled on a daily basis, and concentrate feeds were sampled weekly to characterize their chemical composition.

In week 9 of the experimental period, rumen samples were collected over two consecutive days for analysis of the FA profile and for DNA extraction for the study of the ruminal microbial community. Sampling was performed at 00:00 and 12:00 $\mathrm{h}$ on the first day and at 06:00 and 18:00 $\mathrm{h}$ on the second day. Ruminal samples were collected from each dairy cow using a stomach tube (18 $\mathrm{mm}$ diameter and $160 \mathrm{~cm}$ long) connected to a mechanical pumping unit (Vacuubrand ME 2SI, Wertheim, Germany). The ruminal content was filtered using four layers of sterile gases. For FA profile analyses, a $100 \mathrm{~mL}$ pool was made for each cow with $25 \mathrm{~mL}$ of the liquid fraction of each ruminal extraction. For DNA extraction in the study of the ruminal microbial community, another $100 \mathrm{~mL}$ of each ruminal extraction was saved into a container. All samples were immediately stored frozen at $-20 \pm 5{ }^{\circ} \mathrm{C}$ until analysis.

In the last week of the trial, a composite milk sample $(36 \mathrm{~kg})$ from each treatment was taken in stainless steel milk cans for subsequent sensory analysis.

\subsection{Sample Handling and Laboratory Procedures}

\subsubsection{Feed}

Basal forage and concentrates were dried in a forced-air oven $\left(60^{\circ} \mathrm{C} / 48 \mathrm{~h}\right)$ and ground through a $1 \mathrm{~mm}$ sieve. The samples were analyzed for dry matter (method 934.01) and $\mathrm{N}$ 
(method 984.13) content following AOAC [14]. Neutral detergent fiber was determined by the method of [15] with the use of an alpha amylase but without sodium sulfite and was expressed free of ash. The acid detergent fiber, expressed exclusive of residual ash, was determined by the method of [16]. The ether extract content was determined without hydrolysis by the automated soxhlet method (Soxtec System HT 1043 Extraction Unit, Madrid, Spain) using hexane for $6 \mathrm{~h}$ as solvent. The starch content was measured by polarimetry [17].

Fatty acid methyl esters (FAME) of lipid in both concentrates were prepared in a 1-step extraction-trans-esterification procedure using chloroform and $20 \mathrm{~mL} / \mathrm{L}$ sulfuric acid in methanol [18]. Methyl esters were separated and quantified with a gas chromatograph (Agilent 7890A GC System, Santa Clara, CA, USA) equipped with a flame-ionization detector, a $100 \mathrm{~m}$ fused silica capillary column ( $0.25 \mathrm{~mm}$ i.d., $0.2-\mu \mathrm{m}$ film thickness; CP-SIL 88, CP7489, Varian Ibérica S.A., Madrid, Spain), and hydrogen as the carrier gas (207 kPa, $2.1 \mathrm{~mL} / \mathrm{min})$. The total FAME profile in a $2 \mu \mathrm{L}$ sample volume at a split ratio of 1:50 was determined using the temperature gradient program described in [18]. Peaks were identified based on retention time comparisons with commercially available standard FAME mixtures (Nu-Chek Prep., Elysian, MN, USA; and Sigma-Aldrich, Madrid, Spain).

\subsubsection{Rumen Fatty Acid Profile Analysis}

Rumen FA profile determinations were performed as described in [19]. Briefly, lipid in $200 \mathrm{mg}$ freeze-dried rumen samples was extracted with a mixture of hexane and isopropanol (3:2, vol/vol; [18]) and converted to FAME by sequential base-acid catalyzed transesterification [20]. The total FAME profile was analyzed by gas chromatography using the same chromatograph and temperature gradient program utilized for the analysis of FA in feeds, but isomers of 18:1 were further resolved in a separate analysis under isothermal conditions at $170{ }^{\circ} \mathrm{C}$ [18]. Peaks were identified based on retention time comparisons with the same FAME mixtures used for the analysis of feeds and other commercially available standards (from Nu-Chek Prep.; Sigma-Aldrich; and Larodan, Solna, Sweden), cross referencing with chromatograms reported in the literature (e.g., [18,20]), and based on a comparison with reference samples for which the FA composition was determined based on gas chromatography analysis of FAME and gas chromatography-mass spectrometry analysis of corresponding 4,4-dimethyloxazoline derivatives [20].

\subsubsection{Rumen DNA Extraction}

Rumen samples were thawed for $10 \mathrm{~h}$ at refrigeration temperature $\left(5 \pm 3{ }^{\circ} \mathrm{C}\right)$ and squeezed using four layers of sterile gases to separate between solid (particle size smaller than the diameter of the stomach tube) from liquid digesta phases. Liquid digesta phase was separated into planktonic organisms and bacteria associated with the liquid fraction. The solid phase was separated between associated and adherent fractions following the methodology described in [21]. The four fractions obtained were lyophilized and composited to obtain a unique sample with the four fractions represented proportionally (on dry matter basis). DNA extraction was performed using the commercial Power-Soil DNA Isolation kit (Mo Bio Laboratories Inc, Carlsbad, CA, USA) following manufacturer's instructions. The extracted DNA was subjected to paired-end Illumina sequencing of the V4 hypervariable region of the $16 \mathrm{~S}$ rRNA [22] and of the V7 region of the 18S rRNA genes. The libraries were generated by means of Nextera kit. The $250 \mathrm{bp}$ paired-end sequencing reactions were performed on a MiSeq platform (Illumina, San Diego, CA, USA). The bacterial and archaeal communities were grouped as OTUs (Operational Taxonomic Units) based on 16S rRNA similarities and protozoal and fungi on 18S rRNA similarities. Data processing was performed using QIIME (v.1.9.0): Quantitative Insights Into Microbial Ecology software package [23]. Sequences were clustered as operational taxonomic units (OTUs) of 97\% similarity using UCLUST [24]. OTUs were checked for chimeras using the RDP gold database and assigned bacterial and archaeal 16S RNA taxonomy using the Greengenes database [25], whereas protozoal and fungi 18S rRNA genes were aligned 
against the 18S SILVA database [26]. Alpha and beta diversity metrics were calculated using the QIIME pipeline.

\subsubsection{Milk}

Milk fat, protein, and lactose contents were analyzed by near-infrared spectroscopy (Foss System 4000, Foss Electric, Hillerød, Denmark; ILL, Lekunberri, Spain). To analyze the milk FA profile, milk fat extraction was carried out according to ISO 14156 [27], methylated according to ISO 15884 [28], and analyzed using gas chromatography. The upper phase was injected into a gas chromatograph (Varian 3800) equipped with a capillary column (Cp-sil 88 to over $50 \mathrm{~m}$ ) and the FID detector. Working conditions were set according to the standard [29]. The carrier gas, nitrogen with a pressure of $14 \mathrm{psi}$, was used, and the injector temperature was $250^{\circ} \mathrm{C}$. Temperature program proposed by Kramer et al. [30] was used: 4 min at $45^{\circ} \mathrm{C}$, then an increase in temperature of $13^{\circ} \mathrm{C}$ per minute up to a temperature of $175^{\circ} \mathrm{C}(27 \mathrm{~min})$, and an increase in temperature of $4{ }^{\circ} \mathrm{C}$ per minute up to $215^{\circ} \mathrm{C}$ ( $\left.35 \mathrm{~min}\right)$.

\subsubsection{Pasteurized Milk Perceptibility and Sensory Properties}

Raw milk was pasteurized at $72{ }^{\circ} \mathrm{C}$ for $30 \mathrm{~s}$ using a continuous plate heat exchanger (ATA Tecnología Alimentaria, Irun, Spain). A triangle test was performed to analyze the consumers' ability to distinguish differences between samples for the attributes of appearance, flavor, odor, texture, and overall acceptability. Forty untrained panelists evaluated four milk samples per treatment in private booths. The panelists were served 2 sets of samples in which the reference was either milk from the CTR or CPRC diet. In every set, one sample was identical to the reference and one was different. For each sample set, the panelists had to identify the sample that tasted the same as the reference. The acceptance test was carried out using a non-trained sensory panel of women and men, regular consumers of cow milk. A 9-point line scale was used, with 1 being the lowest and 9 being the highest score, for each of the measured attributes.

\subsection{Calculations and Statistical Analysis}

Milk fat, protein, and lactose concentrations were calculated as weighted average of milking data: $3.5 \%$ fat corrected milk $(\mathrm{FCM})$ was calculated as $0.4318 \mathrm{M}+16.23 \mathrm{~F}$, with $\mathrm{M}$ being milk production $(\mathrm{kg})$ and $\mathrm{F}$ being milk fat $(\mathrm{kg})$.

For statistical purposes, each cow was considered the experimental unit $(n=18)$. Milk yield, FCM, milk fat and protein contents, and milk fat and protein yield were analyzed by a MIXED model for repeated measures using the MIXED procedure of SAS software [31], assuming a covariance structure fitted on the basis of Schwarz's Bayesian information model fit criterion.

$$
Y_{j k l m n}=\mu+\operatorname{Cov}_{j}+T_{k}+P_{l}+W_{m}+C(P)_{n}+\varepsilon_{j k l m n}
$$

where $Y$ is the dependent variable, $\mu$ is the mean values for each treatment, $\operatorname{Cov}$ is the initial record (covariate), $T$ is the fixed effect of the concentrate used, $P$ is the fixed effect of the pair, $W$ is the fixed effect of the week (week 3-week 10), $C(P)$ is the random effect of cow within pair, and $\varepsilon$ is the residuals. Least squares means for treatments are reported.

Rumen FA concentrations were averaged by cow. The rumen and milk FA concentrations were analyzed using the previous statistical model but without considering covariate or repeated measures. The sensorial data $(n=40)$ were analyzed using the previous statistical model but without considering the effect of the week. Treatment means were separated using a Tukey test except for rumen and milk FA profile, where Bonferroni adjustment was used. Significant effects were declared at $p<0.05$.

Relative abundances (RA) of bacterial and eukaryote taxa at the phylum, family, and genus level were analyzed using the MIXED procedure [31], according to the following model:

$$
Y_{j k l}=\mu+T_{j}+P_{k}+C(P)_{l}+\varepsilon_{j k l}
$$


where $Y$ is the dependent variable, $\mu$ is the mean values for each treatment, $T$ is the fixed effect of the concentrate used, $P$ is the fixed effect of the pair, $C(P)$ is the random effect of cow within pair, and $\varepsilon$ is the residuals. Residuals were checked for normality with either the Shapiro-Wilk or Kolmogorov-Smirnov tests using [31], and the data were transformed (log, square-root, and reciprocal transformation) when necessary until the residuals followed a normal distribution.

Significant differences between experimental groups' bacterial and eukaryote community composition were analyzed by analysis of dissimilarity (ADONIS) with 999 permutations. The significant fold changes of the OTUs were tested using DESeq2 [32] and filtered by the false discovery rate value.

To investigate the associations between ruminal FAs and bacterial taxa, a regularized canonical correlation analysis (rCCA) was carried out with the package mixOmics (v6.6.2) [33] in R (v3.5.1) [34]. To perform the rCCA analysis, the correlation values between the RA of bacterial genera and each ruminal FA proportions were computed to calculate a similarity matrix. A clustered image map was inferred using a similarity matrix obtained from the rCCA. A threshold of $\mathrm{R}=0.45$ was used to obtain the relevant components.

\section{Results}

\subsection{Rumen Fatty Acid Composition}

Diet containing CPRC changed the rumen saturated fatty acid (SFA) profile (Table 3). The main changes were significant decreases in the proportions of C12:0 $(p<0.001), \mathrm{C} 14: 0$ $(p=0.019)$, and C16:0 $(p<0.001)$ and increases in the proportions of C17:0 $(p=0.005), \mathrm{C} 18: 0$ $(p=0.007), \mathrm{C} 19: 0(p=0.020), \mathrm{C} 20: 0(p<0.001)$, and C22:0 $(p<0.001)$. The total SFA was lower in the CPRC experimental group $(p<0.001)$.

\section{Escriba aqui la ecuación.}

Table 3. Effect of including cold-pressed rapeseed cake in the concentrate of dairy cows on ruminal saturated fatty acid composition (LSM, $n=18$ ).

\begin{tabular}{ccccc}
\hline Item (g/100 g FA) & CTR & CPRC & SED & $p$-Value \\
\hline C12:0 & 1.99 & 0.33 & 0.144 & $<0.001$ \\
C13:0 & 0.042 & 0.087 & 0.0225 & 0.208 \\
C13:0 iso & 0.041 & 0.044 & 0.0056 & 0.785 \\
C14:0 & 2.94 & 2.07 & 0.195 & 0.019 \\
C15:0 & 0.728 & 0.699 & 0.0482 & 0.554 \\
C15:0 iso & 1.05 & 1.08 & 0.195 & 0.899 \\
C15:0 anteiso & 0.258 & 0.220 & 0.0422 & 0.445 \\
C16:0 & 19.7 & 13.6 & 0.25 & $<0.001$ \\
C16:0 iso & 0.185 & 0.177 & 0.0276 & 0.839 \\
C17:0 & 0.360 & 0.438 & 0.0180 & 0.005 \\
C17:0 iso & 0.200 & 0.215 & 0.0150 & 0.494 \\
C17:0 anteiso & 0.231 & 0.225 & 0.0255 & 0.874 \\
C18:0 & 48.5 & 52.6 & 1.08 & 0.007 \\
C18:0 iso & 0.072 & 0.072 & 0.0045 & 0.980 \\
10-oxo-C18:0 & 0.433 & 0.490 & 0.0576 & 0.436 \\
13-oxo-C18:0 & 0.213 & 0.206 & 0.0207 & 0.790 \\
C19:0 & 0.068 & 0.078 & 0.0024 & 0.020 \\
C20:0 & 0.729 & 0.943 & 0.0222 & $<0.001$ \\
C22:0 & 0.486 & 0.595 & 0.0180 & $<0.001$ \\
C23:0 & 0.136 & 0.145 & 0.0092 & 0.543 \\
C24:0 & 0.581 & 0.571 & 0.0200 & 0.679 \\
C SFA & 79.5 & 75.6 & 0.59 & $<0.001$
\end{tabular}

CTR: control, CPRC: cold-pressed rapeseed cake, SED: standard error of the difference, FA: fatty acid, SFA: saturated fatty acid. 
The diet containing CPRC resulted in an increase in total rumen MUFA $(p=0.002)$, cis MUFA $(p=0.028)$, and trans MUFA $(p=0.002$; Table 4$)$. Shifts were mainly characterized by an increase in the proportions of C18:1 cis-9 $(p=0.028), C 18: 1$ trans-11 $(p=0.005)$, and C18:1 trans-13-14 $(p=0.020)$ but without changing the C18:1 trans-10/trans-11 ratio $(p=0.377)$.

Table 4. Effect of including cold-pressed rapeseed cake in the concentrate of dairy cows on ruminal unsaturated fatty acid composition (LSM, $n=18$ ).

\begin{tabular}{|c|c|c|c|c|}
\hline Item (g/100 g FA) & CTR & CPRC & SED & $p$-Value \\
\hline C14:1 trans-9 & 0.056 & 0.071 & 0.0096 & 0.314 \\
\hline C16:1 cis-7 & 0.104 & 0.111 & 0.0126 & 0.699 \\
\hline C16:1 cis-9 & 0.054 & 0.061 & 0.0055 & 0.403 \\
\hline C16:1 trans-9 & 0.005 & 0.006 & 0.0006 & 0.287 \\
\hline C18:1 cis-9 & 3.66 & 4.48 & 0.204 & 0.028 \\
\hline C18:1 cis-11 & 0.491 & 0.671 & 0.0371 & 0.003 \\
\hline C18:1 cis-12 & 0.805 & 0.778 & 0.0429 & 0.609 \\
\hline C18:1 cis-13 & 0.132 & 0.143 & 0.0081 & 0.165 \\
\hline C18: 1 cis-15 & 0.206 & 0.233 & 0.0113 & 0.096 \\
\hline C18:1 cis-16 & 0.149 & 0.159 & 0.0068 & 0.341 \\
\hline C18:1 trans-4 & 0.198 & 0.259 & 0.0115 & 0.010 \\
\hline C18:1 trans-5 & 0.099 & 0.141 & 0.0041 & $<0.001$ \\
\hline C18:1 trans-6-7-8 & 0.623 & 0.889 & 0.0243 & $<0.001$ \\
\hline C18:1 trans-9 & 0.416 & 0.530 & 0.0346 & 0.058 \\
\hline C18:1 trans-10 & 0.797 & 0.972 & 0.0571 & 0.054 \\
\hline C18:1 trans-11 & 2.68 & 3.55 & 0.140 & 0.005 \\
\hline C18:1 trans-12 & 0.91 & 1.03 & 0.033 & 0.035 \\
\hline C18:1 trans-13-14 & 1.49 & 1.80 & 0.070 & 0.020 \\
\hline C18:1 trans-15 & 1.03 & 1.13 & 0.057 & 0.265 \\
\hline C18:1 trans-16 & 0.763 & 0.855 & 0.0305 & 0.078 \\
\hline C20:1 cis-11 & 0.021 & 0.035 & 0.0035 & 0.027 \\
\hline C22: 1 cis-13 & 0.021 & 0.047 & 0.0013 & $<0.001$ \\
\hline C24:1 cis-15 & 0.087 & 0.130 & 0.0051 & $<0.001$ \\
\hline C18:2 cis-9 cis-12 & 1.70 & 1.47 & 0.119 & 0.223 \\
\hline C18:2 cis- 9 trans-12 & 0.021 & 0.018 & 0.0022 & 0.012 \\
\hline $\mathrm{C} 18: 2$ trans- 11 cis- 15 & 0.259 & 0.311 & 0.0303 & 0.260 \\
\hline C18:2 trans- 9 trans-12 & 0.013 & 0.015 & 0.0015 & 0.441 \\
\hline C18:2 cis- 9 trans-11 CLA & 1.42 & 1.66 & 0.167 & 0.354 \\
\hline C18:2 trans-9 cis-11 CLA & 0.055 & 0.047 & 0.0062 & 0.146 \\
\hline C18:2 trans-10 cis-12 CLA & 0.066 & 0.061 & 0.0067 & 0.523 \\
\hline C18:2 trans-11 trans-13 CLA & 0.039 & 0.050 & 0.0042 & 0.113 \\
\hline C18:3n-3 & 0.389 & 0.453 & 0.0296 & 0.150 \\
\hline$C 20: 2 n-3$ & 0.003 & 0.004 & 0.0006 & 0.307 \\
\hline C20:2n-6 & 0.019 & 0.022 & 0.0022 & 0.426 \\
\hline$C 20: 3 n-6$ & 0.008 & 0.005 & 0.0013 & 0.293 \\
\hline C20:4n-6 & 0.016 & 0.011 & 0.0043 & 0.148 \\
\hline$\sum$ MUFA trans & 9.1 & 11.2 & 0.30 & 0.002 \\
\hline$\sum$ MUFA cis & 5.73 & 6.85 & 0.284 & 0.028 \\
\hline$\sum$ MUFA & 14.8 & 18.1 & 0.45 & 0.002 \\
\hline$\sum$ PUFA & 4.47 & 4.37 & 0.324 & 0.829 \\
\hline$\sum$ CLA & 1.86 & 2.09 & 0.189 & 0.430 \\
\hline$\sum n-3$ & 0.411 & 0.472 & 0.0305 & 0.157 \\
\hline$\sum n-6$ & 0.063 & 0.061 & 0.0078 & 0.803 \\
\hline$n-6: n-3$ & 0.154 & 0.128 & 0.0154 & 0.263 \\
\hline C18:1 trans-10:trans-11 & 0.306 & 0.278 & 0.0235 & 0.377 \\
\hline
\end{tabular}

CTR: control, CPRC: cold-pressed rapeseed cake, SED: standard error of the difference, FA: fatty acid, MUFA: mono-unsaturated FA, PUFA: poly-unsaturated FA, CLA: conjugated linoleic acid.

The total ruminal PUFA contents were not affected $(p=0.829)$ by the diet containing CPRC (Table 4). The experimental concentrate with CPRC did not affect C18:2 cis-9 trans-11 CLA, C18:2 trans-9 cis-11 CLA, C18:2 trans-11 trans-13 CLA, and C18:2 trans-10 cis-12 CLA contents $(p>0.05)$. As a consequence, the diet with CPRC did not result in increased CLA 
proportions $(p=0.430)$. The proportions of long-chain $n$-3 PUFA $(p=0.157)$ and $n-6$ PUFA $(p=0.803)$ were not altered in the CPRC experimental group. As a consequence, the diet with CPRC did not alter the $n-6: n-3$ ratio $(p=0.263)$.

\subsection{Ruminal Microbial Community}

The main phyla were Bacteroidetes (50.7\%) and Firmicutes (33.2\%). Within the Bacteroidetes, the most abundant families were Prevotellaceae (42.4\%), undefined families within the order of the Bacteroidales (4.2\%), and (Paraprevotellaceae) $(1.2 \%)$. The dominant families of Firmicutes were Lachnospiraceae (11.4\%), Ruminococcaceae $(7.3 \%)$, undefined families within order of the Clostridiales (7.3\%), and Veillonellaceae (5.5\%) (Figure 1).

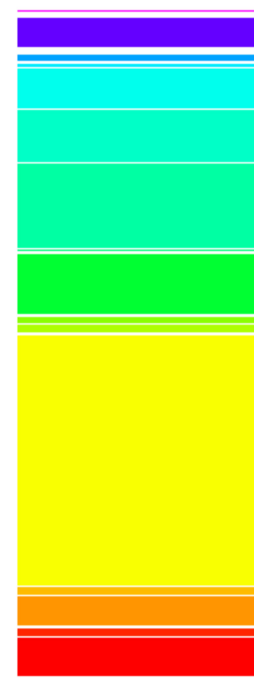

CTR

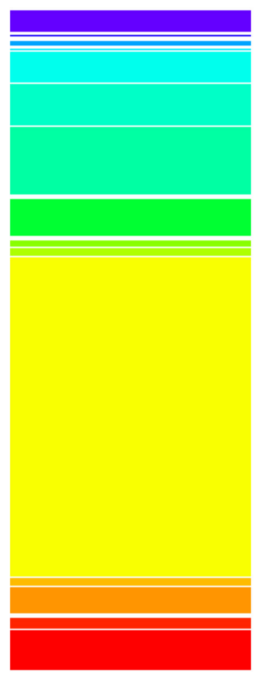

CPRC

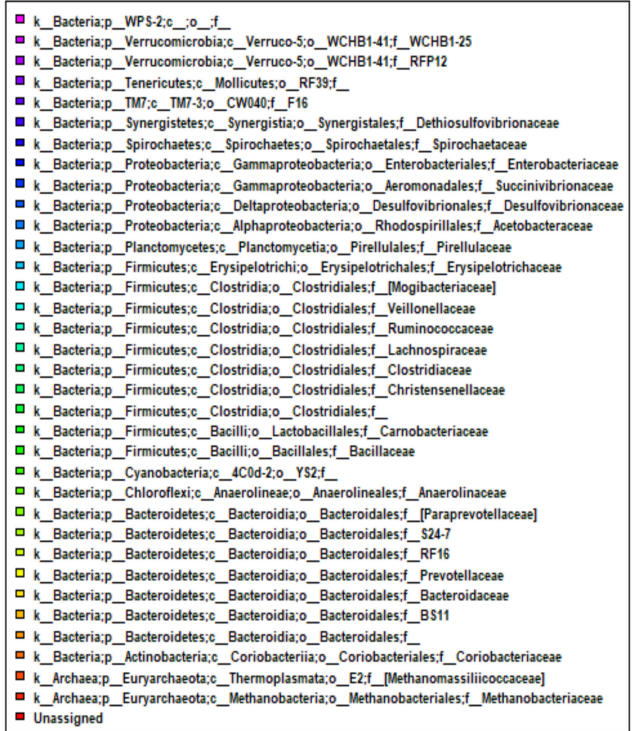

Figure 1. Bacterial community composition at the family level in the ruminal samples of cows $(n=18)$ when fed a control concentrate (CTR) and a concentrate with cold-pressed rapeseed cake (CPRC).

The experimental concentrate with CPRC did not influence the bacterial or Eukaryote species richness as expressed by different diversity indices, such as chao1 or Shannon (Table 5). The beta diversity and the statistical test performed with ADONIS revealed no differences in bacterial $(p=0.186)$ community and a tendency in eukaryote $(p=0.063)$ community between experimental concentrates.

Table 5. Effect feeding cold-pressed rapeseed on ruminal microbiota diversity measurements in lactating cows.

\begin{tabular}{ccccc}
\hline Diversity Indices & \multicolumn{2}{c}{ Treatment } & SEM & $p$-Value \\
\hline 16S rRNA & CTR & CPRC & & \\
Observed OTU & 10,126 & 10,684 & 290.7 & 0.194 \\
Chao1 & 18,641 & 18,994 & 334.5 & 0.466 \\
Phylogenetic diversity & 380 & 390 & 6.1 & 0.286 \\
Shannon & 9.72 & 9.44 & 0.153 & 0.207 \\
Coverage (\%) & 94.2 & 94.8 & 0.20 & 0.051 \\
18S rRNA & & & & \\
Observed OTU & 1336 & 1180 & 77.0 & 0.172 \\
Chao1 & 2453 & 2446 & 137.7 & 0.971 \\
Phylogenetic diversity & 19.7 & 19.0 & 0.90 & 0.609 \\
Shannon & 5.29 & 5.39 & 0.157 & 0.661 \\
Coverage (\%) & 99.4 & 99.3 & 0.04 & 0.215 \\
\hline
\end{tabular}


Among the different bacterial phyla (Supplementary Materials Table S1), the diet containing CPRC only significantly decreased Tenericutes $(p=0.038)$ and tended to decrease Plantomycetes $(p=0.056)$.

At the family level (Supplementary Materials Table S2), the diet with CPRC decreased RA of the undefined families within the order Clostridiales $(p=0.016)$, Christensenellaceae $(p=0.033)$, and the undefined families within the order RF39 $(p=0.024)$ and tended to decrease RA of Lachnospiraceae $(p=0.08)$, Ruminococcaceae $(p=0.08)$, and Pirellulaceae $(p=0.055)$.

At the genus level (Supplementary Materials Table S3), the diet with CPRC increased RA of Ruminococcus ( $p=0.047)$ and decreased RA of Blautia $(p=0.045) ; p-75-\mathrm{a} 5(p=0.013)$; undefined genus within the orders Clostridiales $(p=0.016)$ and RF39 $(p=0.024)$; and those within families Christensenellaceae $(p=0.033)$, Lachnospiraceae $(p=0.011)$, and Ruminococcaceae $(p=0.034)$ and tended to decrease Clostridium $(p=0.098)$, Shuttleworthia $(p=0.0506)$, Pyramidobacter $(p=0.072)$, and undefined genus within the family Pirellulaceae $(p=0.055)$.

At the OTU level, the OTU belonging to the genera Prevotella and Ruminococcus were enriched when the animals were fed the experimental concentrate with CPRC, whereas in the ruminal content of the animals fed the CTR concentrate, an enrichment in OTU of undefined genera within the order Clostridiales was observed (Figure 2).

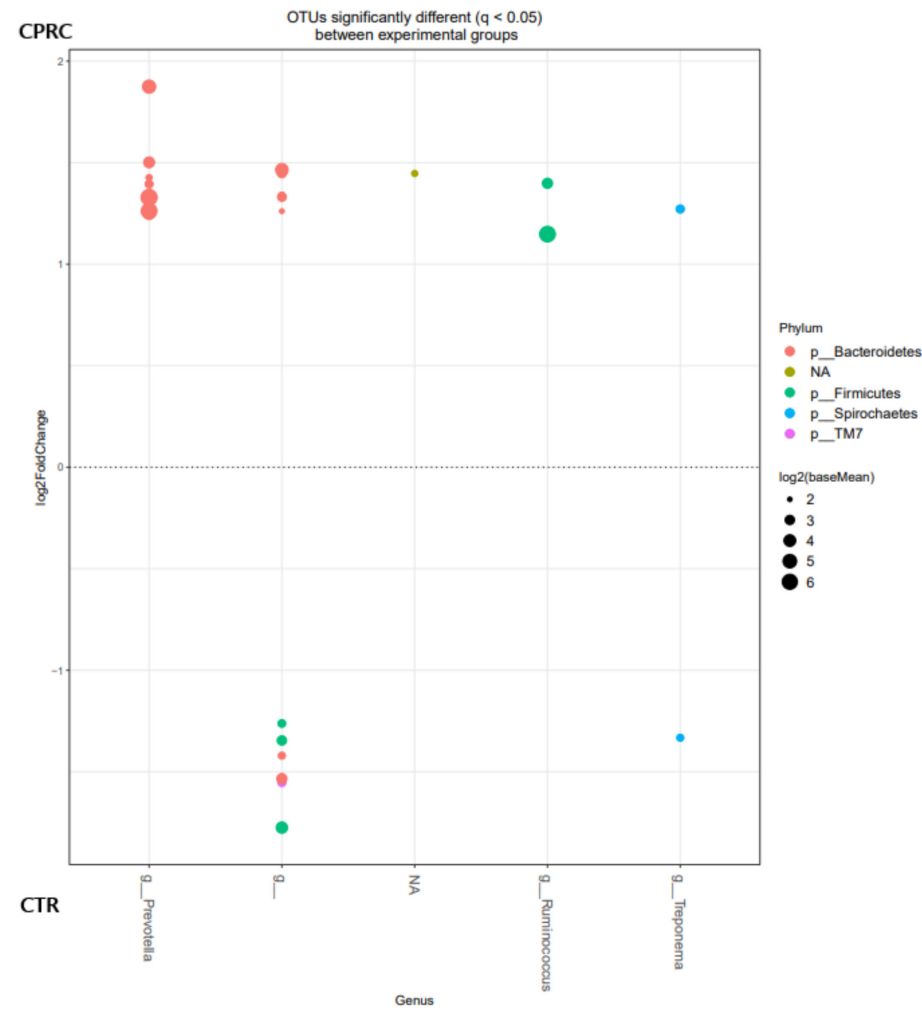

Figure 2. OTUs at the genus level were significantly different $(q<0.05)$ between rumen samples of cows fed the control (CTR; below) and concentrate with cold-pressed rapeseed cake (CPRC; above). Each point represents a single OTU colored by phylum and grouped on the $x$-axis by taxonomy. The size of the point reflects the $\log 2$ mean abundance of the sequence data.

The most abundant Eukaryote phyla (Figure 3 ) in both experimental groups (CPRC and CTR) were Ciliophora (42 and 34\%), Ascomycota (33\% and 32\%), and neocallimastigomycota (4 and 11\%). 

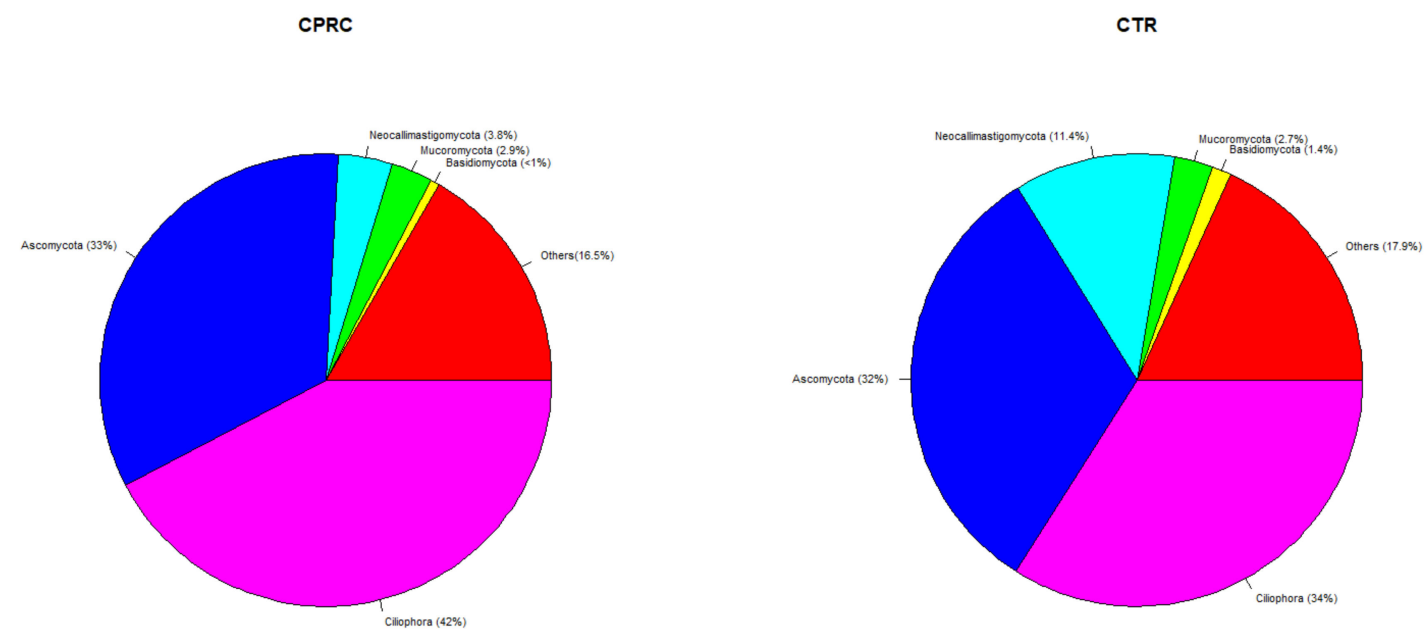

Figure 3. Mean relative abundances of Eukaryote phyla in the rumen samples of cows fed a concentrate with cold-pressed rapeseed cake (CPRC) or a control concentrate (CTR). "Others" include phyla with relative abundance $<0.1 \%$ and phyla related to feed and the host (Charophyta, Chlorophyta, and Chordata).

Among the different Eukaryote phyla (Supplementary Materials Table S1), diets with CPRC only significantly decreased neocallimastigomycota $(p=0.016)$ compared with the control (Figure 4).

(a)

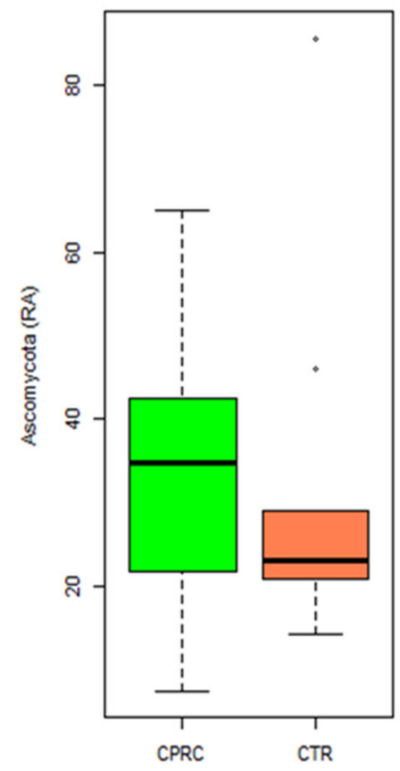

(b)

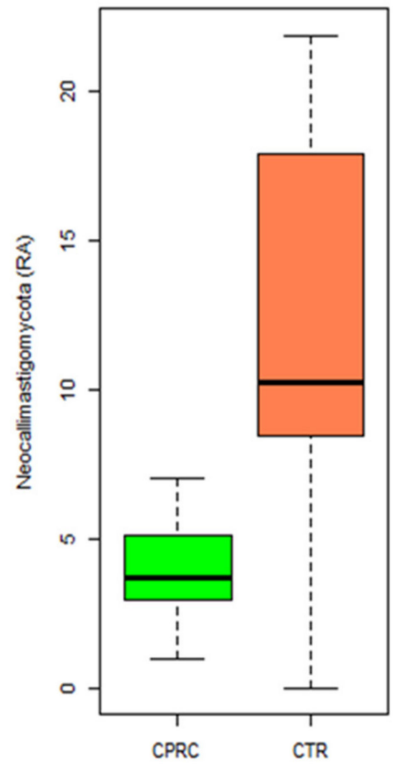

(c)

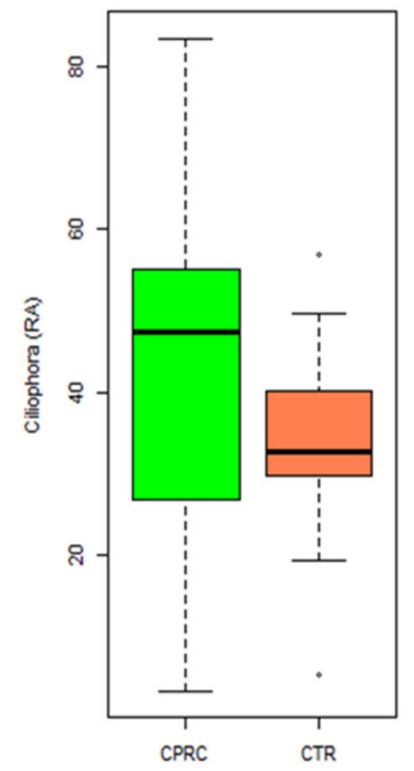

Figure 4. Relative abundances of the three main Eukaryote phyla in rumen samples of cows fed a concentrate with cold-pressed rapeseed cake (CPRC) or a control concentrate (CTR). (a) Relative abundance of Ascomycota, (b) relative abundance of Neocallimastigomycota, and (c) relative abundances of Ciliophora.

Regarding the genera belonging to Ciliophora phylum, diets containing CPRC only significantly increased the RA of genus Entodinium ( $p=0.039$; Table 6). At the OTU level (Supplementary Table S4), some OTUs belonging to the genera Entodinium, undefined genus within subclass Trichostomatia, and Ophryoscolex were enriched in the rumen of animals fed the experimental concentrate with CPRC, whereas in the ruminal content of the animals fed the CTR concentrate, enrichments in OTUs of the undefined genus within subclass Haptoria, Ophryoscolex, and undefined genus within family Neocallimastigaceae were observed. 
Table 6. Relative abundances (\% of total ciliphora sequences) of Protozoal genera in the rumen digesta samples of cows fed a concentrate with cold-pressed rapeseed cake or a control concentrate.

\begin{tabular}{ccccc}
\hline Genus & \multicolumn{2}{c}{ Treatment } & SEM & $p$-Value \\
\hline Entodinium & CTR & CPRC & & \\
Diplodinium & 15.0 & 23.9 & 2.76 & 0.039 \\
Dasytricha & 3.2 & 5.7 & 2.22 & 0.442 \\
Isotricha & 6.6 & 5.3 & 1.75 & 0.615 \\
Ophryoscolex & 12.6 & 7.6 & 2.86 & 0.232 \\
Platyophryida & 2.6 & 2.1 & 0.89 & 0.675 \\
Eremoplastron & 0.03 & 1.34 & 0.808 & 0.269 \\
Eudiplodinium & 0.003 & 0.018 & 0.0079 & 0.195 \\
Polyplastron & 0.0003 & 0.0002 & 0.00018 & 0.683 \\
udG_Trichostomatia & 0.005 & 0.008 & 0.0042 & 0.596 \\
udG_Haptoria & 56.9 & 52.9 & 4.37 & 0.521 \\
udG_Litostomatea & 2.9 & 0.4 & 1.30 & 0.204 \\
Other groups ${ }^{\text {a }}$ & 0.012 & 0.012 & 0.0026 & 0.844 \\
\hline
\end{tabular}

CTR: control concentrate; CPRC: concentrate with cold-pressed rapeseed cake; SEM: standard error of the mean a: relative abundance $<0.5 \%$ in any one sample; udG: undefined genera.

The associations between rumen FA and bacterial taxa were represented by a clustered image map (Figure 5) inferred from the rCCA analysis. Genera Ruminococcus, Anaerovibrio, Butyrivibrio, Bulleidia, Methanosphaera, SHD231, Mogibacterium, and Methanobrevibacter and undefined genera within the families Veillonellaceae and Coriobacteriaceae were positively correlated with the total MUFA and some BH intermediates (C18:1 trans4, C18:1 trans-5, C18:1 trans 6-7-8, C18:1 trans-9, C18:1 trans-10, C18:1 trans-12, C18:1 trans13-14, C18:1 trans-15, C18:1 trans-16, C18:1 cis-11, C18:1 cis-9, C18:2 trans-11 cis-15, and C22:1 cis13) while these FA were negatively correlated with the genera Clostridium, Succiniclasticum, Lachnospira, Blautia, Pyramidobacter, Pseudobutyrivibrio, and Coprococcus; undefined genera within order Clostridiales and RF39; and undefined genera within families S247, Ruminococcaceae, and Lacnospiraceae.

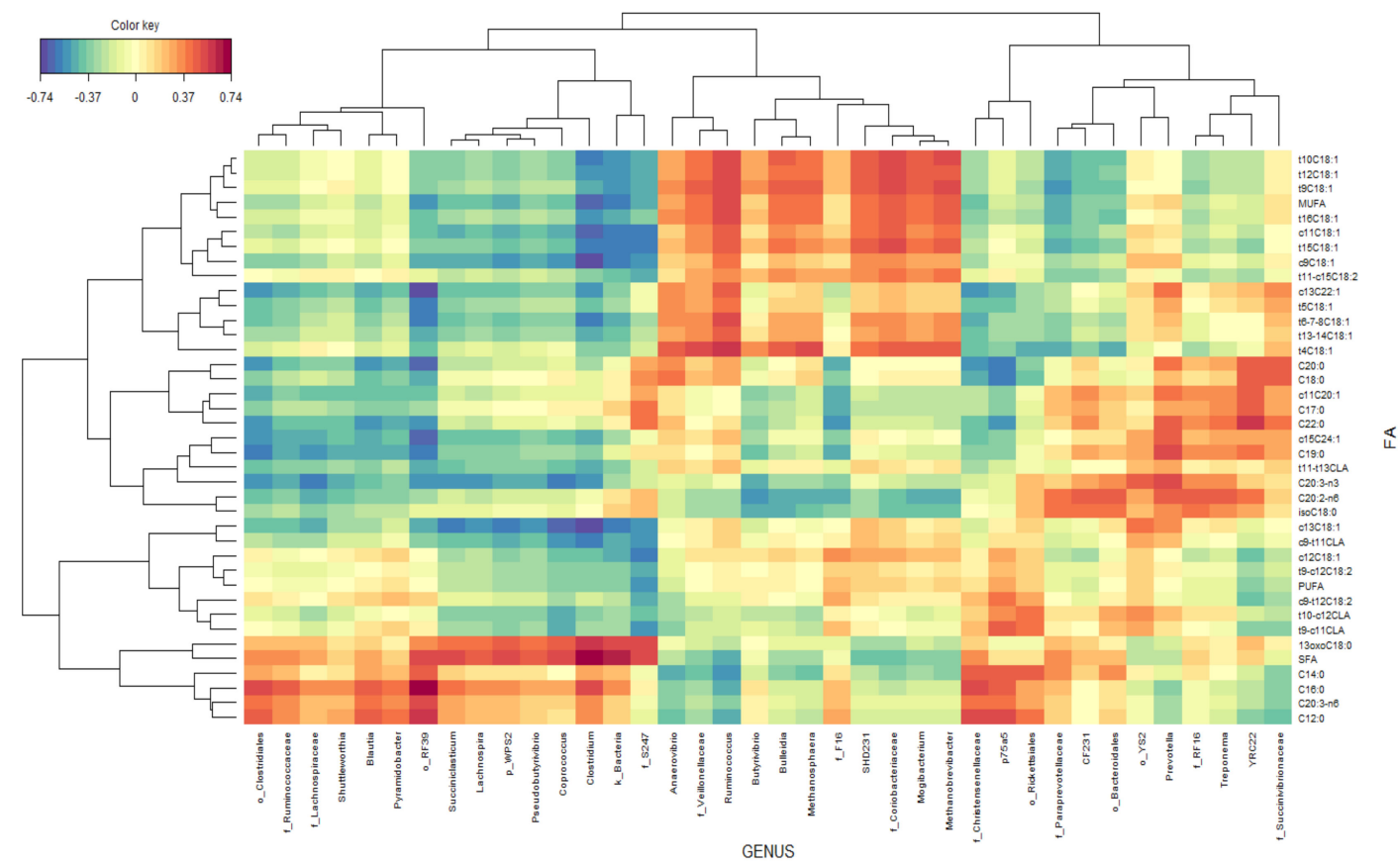

Figure 5. Associations between bacterial genus and ruminal fatty acid proportions independent of the experimental group. Clustered image map based on the regularized canonical correlations between bacterial relative abundances at the genus level and ruminal proportions of fatty acids. Significative correlations are colored following the key shown. 
Genera Clostridium, Succiniclasticum, Lachnospira, Blautia, Pyramidobacter, Pseudobutyrivibrio, and Coprococcus; undefined genera within orders Clostridiales and RF39; and undefined genera within families S247, Ruminococcaceae, and Lacnospiraceae were positively correlated with total SFA, concretely with C12:0, C14:0, C16:0, and 13-oxo C18:0, while these FA were negatively correlated with genera Ruminococcus and Anaerovibrio and undefined genera within family Veillonellaceae.

Genera Prevotella, Treponema, YRC22, CF231, Ruminococcus, and Anaerovibrio and undefined genera within families Succinivibrionaceae, Paraprevotellaceae, and S247 were positively correlated with long chained saturated fatty acids, concretely with C17:0, C18:0, C19:0, C20:0, and C22:0, while these FA were negatively correlated with genera p-75-a75, Butyrivibrio, Clostridium, Coprococcus, Blautia, and Shuttleworthia; undefined genera within families Chistensenellaceae, RF16, Ruminococcaceae, and Lacnospiraceae; and undefined genera within orders RF39 and Clostridiales.

\subsection{Milk Fatty Acid Composition}

The proportions of most short and medium chain SFA were not modified by the dietary treatments (Table 7), except for C13:0, which was increased in the milk fat of CPRC-fed cows $(p=0.043)$.

Table 7. Effect of including cold-pressed rapeseed cake in the concentrate of dairy cows on milk saturated fatty acids composition (LSM, $n=18$ ).

\begin{tabular}{ccccc}
\hline & CTR & CPRC & SED & $p$-Value \\
\hline FA (g/100 g FA) & & & & \\
C4:0 & 3.27 & 3.11 & 0.137 & 0.273 \\
C6:0 & 1.80 & 1.86 & 0.059 & 0.353 \\
C8:0 & 0.695 & 0.814 & 0.0560 & 0.143 \\
C10:0 & 2.34 & 2.60 & 0.138 & 0.233 \\
C11:0 & 0.034 & 0.041 & 0.0026 & 0.077 \\
C12:0 & 3.46 & 3.25 & 0.171 & 0.427 \\
C13:0 & 0.061 & 0.073 & 0.0033 & 0.043 \\
C14:0 iso & 0.096 & 0.081 & 0.0064 & 0.057 \\
C14:0 & 12.2 & 12.0 & 0.37 & 0.734 \\
C15:0 anteiso & 0.210 & 0.205 & 0.0092 & 0.610 \\
C15:0 & 0.881 & 0.924 & 0.0469 & 0.520 \\
C16:0 & 31.0 & 28.7 & 1.08 & 0.192 \\
C17:0 & 0.364 & 0.391 & 0.0080 & 0.057 \\
C18:0 & 10.8 & 11.8 & 0.55 & 0.251 \\
C20:0 & 0.146 & 0.163 & 0.0069 & 0.133 \\
C21:0 & 0.038 & 0.037 & 0.0017 & 0.734 \\
C23:0 & 0.030 & 0.029 & 0.0017 & 0.560 \\
C24:0 & 0.052 & 0.049 & 0.0030 & 0.451 \\
LBCFA & 0.783 & 0.742 & 0.0282 & 0.276 \\
ISFA & 70.9 & 69.6 & 1.05 & 0.413 \\
De Novo & 42.1 & 41.1 & 0.88 & 0.443 \\
\hline FA: Fatty acids; BCFA: Branched-chain fatty acids; SFA: saturated fatty acid; CTR: control; CPRC: cold-pressed \\
rapeseed cake; SED: standard error of the difference. & &
\end{tabular}

The diet with CPRC did not modify the milk proportions of C18:1 cis-9 $(p=0.628)$, C18:1 cis-11 ( $p=0.427)$, or C18:1 trans-11 ( $p=0.650)$ but increased C18:1 trans-6 $(p=0.001)$, C18:1 trans-10 $(p=0.034)$, and C18:1 trans-12 $(p=0.043)$. The total MUFA $(p=0.495)$, cis MUFA $(p=0.633)$ and trans MUFA $(p=0.062)$ were not modified when the CPRC diet was fed.

As shown in Table 8, feeding a diet with CPRC did not affect the total PUFA in milk $(p=0.625)$. The use of CPRC did not affect milk fat C18:2 cis-9 trans-11 CLA $(p=0.834)$ or total CLA $(p=0.711)$ but reduced C18:3n-6 $(p=0.043)$ and increased C18:3n-3 $(p=0.008)$ and C20:1n-9 cis-11 $(p<0.001)$ proportions. The milk ratio of PUFA:SFA did not differ 
between treatments $(p=0.507)$, whereas the n6:n3 ratio was lower in the CPRC experimental group $(p=0.028)$.

Table 8. Effect of including cold-pressed rapeseed cake in the concentrate of dairy cows on milk unsaturated fatty acids composition (LSM, $n=18$ ).

\begin{tabular}{ccccc}
\hline & CTR & CPRC & SED & $p$-Value \\
\hline FA (g/100 g FA) & & & & \\
C18:1 cis-9 & 22.7 & 23.4 & 0.96 & 0.628 \\
C18:1 cis-11 & 0.265 & 0.256 & 0.0092 & 0.427 \\
C18:1 trans-6 & 0.601 & 0.772 & 0.0366 & 0.001 \\
C18:1 trans-10 & 0.386 & 0.511 & 0.0362 & 0.034 \\
C18:1 trans-11 & 1.00 & 1.05 & 0.078 & 0.650 \\
C18:1 trans-12 & 0.394 & 0.456 & 0.0200 & 0.043 \\
C18:2 trans-9 trans-12 & 0.049 & 0.043 & 0.0061 & 0.536 \\
C18:2 cis-9 cis-12 & 1.84 & 1.88 & 0.106 & 0.782 \\
C18:2 cis-9 trans 11 CLA & 0.666 & 0.676 & 0.0451 & 0.834 \\
C18:3n-6 & 0.025 & 0.021 & 0.0013 & 0.043 \\
C18:3n-3 & 0.262 & 0.326 & 0.0123 & 0.008 \\
C20:1n-9 cis-11 & 0.044 & 0.062 & 0.0019 & $<0.001$ \\
C20:2n-6 & 0.021 & 0.022 & 0.0007 & 0.341 \\
C20:3n-6 & 0.078 & 0.070 & 0.0037 & 0.155 \\
C20:4n-6 & 0.024 & 0.024 & 0.0015 & 0.952 \\
C20:3n-3 & 0.113 & 0.110 & 0.0057 & 0.394 \\
C22:2n-6 & 0.037 & 0.035 & 0.0017 & 0.341 \\
C22:6n-3 & 0.051 & 0.050 & 0.0026 & 0.537 \\
C24:1n-9 & 0.011 & 0.012 & 0.0007 & 0.239 \\
$\sum$ cis MUFA & 23.0 & 23.7 & 0.96 & 0.633 \\
$\sum$ trans MUFA & 2.38 & 2.79 & 0.154 & 0.062 \\
$\sum$ MUFA & 28.0 & 29.1 & 1.00 & 0.495 \\
$\sum$ PUFA & 3.43 & 3.53 & 0.142 & 0.625 \\
$\sum$ CLA & 0.901 & 0.928 & 0.0482 & 0.711 \\
n-6: $n$ - 3 & 0.394 & 0.487 & 0.0261 & 0.045 \\
PUFA:SFA & 4.68 & 4.24 & 0.173 & 0.028 \\
C18:1 trans-10 & 0.049 & 0.051 & 0.0024 & 0.507 \\
\hline
\end{tabular}

FA: fatty acids; MUFA: monounsaturated fatty acids; PUFA: polyunsaturated fatty acids; CLA: conjugated linoleic acid. SFA: saturated fatty acids; CTR: control; CPRC: cold-pressed rapeseed cake; SED: standard error of the difference.

\subsection{Milk Yield and Milk Composition}

The milk composition in terms of crude fat $(p=0.100)$, crude protein $(p=0.203)$, or lactose $(p=0.556)$ proportions did not differ in the experimental group fed a diet with CPRC compared with the control group (Table 9). Similarly, feeding a diet with CPRC did not affect the yields of milk $(p=0.304), \operatorname{FCM}(p=0.679)$, crude fat $(p=0.633)$, crude protein $(p=0.616)$, or lactose $(p=0.485)$.

\subsection{Pasteurized Milk Perceptibility and Sensory Properties}

In the triangle test, consumers were able to differentiate between the milk of the CTR and CPRC groups $(p<0.001)$. Feeding a diet with CPRC enhanced the overall acceptability by 0.43 points out of $9(p=0.047)$ and by improving the flavor by 0.52 points out of 9 $(p=0.021)$. Appearance, odor, or texture were not perceived being as different $(p>0.05$; Table 10) 
Table 9. Effect of feeding cold-pressed rapeseed cake on milk yield and composition of lactating dairy cows (LSM, $n=18)$.

\begin{tabular}{cccccc}
\hline & \multicolumn{2}{c}{ Treatments } & SED & \multicolumn{2}{c}{$p$-Value } \\
\hline & CTR & CPRC & & Week & Treatment \\
\hline Milk yield, kg/d & 23.8 & 25.2 & 0.97 & $<0.001$ & 0.304 \\
Milk fat, \% & 4.00 & 4.35 & 0.175 & 0.043 & 0.100 \\
Yield, kg/d & 0.946 & 0.954 & 0.0614 & 0.004 & 0.633 \\
3.5\% FCM, kg/d & 25.7 & 28.7 & 1.90 & $<0.001$ & 0.179 \\
Milk crude protein, \% & 3.30 & 3.42 & 0.064 & $<0.001$ & 0.203 \\
Yield, kg/d & 0.752 & 0.790 & 0.0541 & 0.003 & 0.616 \\
Milk lactose, \% & 4.89 & 4.86 & 0.035 & 0.609 & 0.556 \\
Yield, kg/d & 1.09 & 1.19 & 0.108 & 0.002 & 0.485 \\
\hline
\end{tabular}

FCM: fat corrected milk; CPRC: cold-pressed rapeseed cake; CTR: control; SED: standard error of the difference.

Table 10. Effect of feeding cold-pressed rapeseed cake on milk sensorial quality of lactating dairy cows $(n=40)$.

\begin{tabular}{ccccc}
\hline & CTR & CPRC & SED & $p$-Value \\
\hline Overall & 5.83 & 6.26 & 1.646 & 0.047 \\
acceptability & 6.67 & 6.80 & 1.414 & 0.494 \\
Appearance & 5.86 & 5.90 & 1.403 & 0.818 \\
Odour & 6.14 & 6.47 & 1.455 & 0.080 \\
Texture & 5.47 & 5.99 & 1.756 & 0.021 \\
Flavour &
\end{tabular}

CTR: control; CPRC: cold-pressed rapeseed cake; SED: standard error of the difference.

\section{Discussion}

The proportion of total SFA and specifically short/medium-chain FA (C12:0, C14:0, and $\mathrm{C} 16: 0)$ in the ruminal liquid mimicked that of the diets and is in agreement with the changes observed in other in vitro studies using CPRC [9]. Moreover, feeding a concentrate with CPRC induced some relevant changes related to the ruminal FA BH process. Although the total SFA decreased in rumen fluid in diets with CPRC, the C18:0-C22:0 proportions increased. The main FAs present in the experimental concentrates were C18:1 cis-9 ( $23.4 \mathrm{vs.}$ $41.0 \mathrm{~g} / 100 \mathrm{~g}$ FA for CTR and CPRC, respectively) and C18:2 cis9 cis12 (35.0 vs. $32.7 \mathrm{~g} / 100 \mathrm{~g}$ FA for CTR and CPRC, respectively). These FA were subjected to a $\mathrm{BH}$ process in the rumen carried out by ruminal bacteria that ended up in the formation of C18:0 [35]. The higher proportion of ruminal C18:0 found with CPRC can be due to the fact that the CPRC diet provided greater amounts of C18 UFAs compared with the CTR diet. Other authors have observed the same trends using CPRC [9] and cold-pressed sunflower cake, also rich in C18 UFAs [36].

Plant lipid sources rich in UFA have been related to an increase in the C18:1 production in the rumen $[37,38]$. The extent of rumen $\mathrm{BH}$ of $\mathrm{C} 18$ UFAs is known to vary between 58 and $100 \%$ [39]. However, it is important to highlight that the final reduction step of UFA to C18:0 is considered rate limiting, and therefore, C18:1 intermediates (mainly C18: trans-11) can accumulate and flow out of the rumen, mainly when excessive amounts of UFA are ingested $[40,41]$. Considering the higher ruminal proportions of total MUFA, especially C18:1 cis-9, and total trans-MUFA, especially C18:1 trans-11, this seemed to be the case when feeding a diet with CPRC in the present study.

Moreover, an effect of the type of fat present in the CPRC on the microorganisms involved in the $\mathrm{BH}$ process cannot be precluded. Huws et al. [42] proposed that uncultured bacteria belonging to genera Anaerovorax, Prevotella, Lachnospiraceae Incertae Sedis, Ruminococcus, Butyrivibrio, Pseudobutyrivibrio, Tanerella, unclassified Bacteroidales, Clostridia and Clostridiales, Ruminococcaceae, Lachnospiraceae, Prevotellaceae, and Porphyromonadaceae might be implicated in ruminal C18:1 trans-11 formation. Other authors also stated that other genera including genus Ruminococcus, as one of the most prevalent in the rumen, are involved in ruminal C18: trans- 11 formation [43]. In this sense, we observed an 
increase in the RA of genera Ruminococcus and some OTUs of genus Prevotella with CPRC, whereas Clostridium and the undefined genus within family Lachnospiraceae RA decreased with CPRC. However, although C18:1 trans-11 ruminal concentrations increased with diets containing CPRC, no direct relationship of any specific bacterial genus was observed with C18:1 trans-11 in the present study. Although bacterial species involved in ruminal C18:1 trans-10 formation are not well known, some authors observed ruminal formation of this FA by Ruminococcus albus [43,44]. In agreement with these observations we observed an increased RA in genus Ruminococcus in the CPRC experimental group, and this genus presented a positive relationship with $\mathrm{C} 18: 1$ trans-10 concentrations in the rumen contents in the clustered image map.

Regarding the last step of ruminal $\mathrm{BH}$, although Butyrivibrio proteoclasticus is the only bacterial species known to reduce C18:1 FA to C18:0 [35,45], non-cultivated Butyrivibrio, Pseudobutyrivibrio, and other unknown Lachnospiraceae strains could play a role in the final BH step [46]. In the current study, only the RA of Blautia (family Lachnospiraceae) and undefined genera within family Lachnospiraceae were decreased in ruminal contents of cows fed a diet with CPRC. Furthermore, there was a negative correlation between these taxa and trans $\mathrm{C} 18: 1$ intermediates, potentially suggesting that these genera were involved in ruminal 18:0 formation though minor BH pathways [47]. The RA of the order RF39 was also decreased in cows fed with CPRC and was negatively correlated with 18:1 isomers, which agrees with the results observed in [48] when supplementing a fat rich in PUFA to goats. These authors hypothesized that genera within this order might also be implicated in ruminal 18:0 formation, a hypothesis that is also supported by our results. Another alternative explanation is that feeding CPRC reduced the biohydrogenating activity of B. proteoclasticus instead of its RA, but to test this hypothesis, metatranscriptomic assays should be performed and are far from the objective of the present study.

The use of a diet with CPRC seemed not to affect the first steps of the $\mathrm{BH}$ pathway of C18:2 in the rumen, since neither the main intermediate C18:2 cis-9 trans 11 CLA proportion nor the proportions of other minor alternative intermediates proportions were altered in the rumen [43]. This may be explained by the great extent of ruminal $\mathrm{BH}$ that happens with linoleic acid (up to $95 \%$; [49]). For the C18:3 $\mathrm{BH}$ process, none of the main intermediates of the first stages of the $\mathrm{BH}$ process seemed to be affected by the diet with CPRC. However, some alternative pathways seemed to be affected. Dewanckele et al. [43] showed that a minor intermediate pathway for $\mathrm{BH}$ of $\mathrm{C} 18: 3$ in the rumen was the hydrogenation and isomerizarion to C18:2 cis-12,cis15 and C18:2 trans-12,cis-15 and the posterior hydrogenation to some C18:1 isomers (C18:1 cis-11, C18:1 cis-12, C18:1 trans-12, C18:1 cis-15, C18:1 trans-15, and C18:1 trans-16), which were finally hydrogenated to C18:0. We observed that some of these intermediates (C18:1 cis-11, C18:1 trans-12, C18:1 cis-15, and C18:1 trans-16) increased in the rumen of cows of the CPRC group. This would be related to an inhibitory effect of the lipids present in the CPRC on the last step of $\mathrm{BH}$ of these FA to C:18:0. As mentioned before, some unknown Lachnospiraceae strains might play a role in the final $\mathrm{BH}$ step [46]. In this sense, we observed a negative relationship of these intermediates with the RA of Blautia (family Lachnospiraceae) and the undefined genera within family Lachnospiraceae, and we also observed that the RA of these genera was decreased in the ruminal contents of cows fed a diet with CPRC.

The contribution of protozoa and fungi in the rumen to the $\mathrm{BH}$ process has been reported as negligible and mainly associated with activity of protozoa ingested bacteria $[50,51]$. However, it is recognized that rumen protozoa contain proportionally more UFA than rumen bacteria and thus could play an important role in increasing CLA or C18:1 trans-11 ruminal proportions and can contribute in a significant way to the flow of UFAs leaving the rumen [52-54]. This is in agreement with the increased RA of some rumen ciliates and the increased ruminal C18:1 trans- 11 concentration in the ruminal content of CPRC experimental group. Conversely, some authors reported decreased ciliate protozoa when rapeseed oil was included in the diet of sheep [55]. However, the level of inclusion and the physical form of the fat supplement could play a role in the effect towards pro- 
tozoa population. In addition, Newbold et al. [56] suggested that, although high dietary lipid concentration is toxic to protozoa, the antiprotozoal effect of fat depends on the FA composition, with medium chain FA being more effective in reducing ciliates than PUFA.

In the present paper, increasing the dietary UFA content with the use of CPRC in the cow ration did not have a great effect on microbial populations diversity (alpha and beta diversity indices) but led to changes in some bacterial and eukaryotic taxa. However, CRPC partially replaced other ingredients in the concentrate. In this regard, differences not only in the FA profile but also in the chemical composition of both concentrates evaluated cannot be ignored and might also contribute to explain some subtle differences in ruminal microbial populations. It was observed that these changes could modify the $\mathrm{BH}$ process in the rumen. However, changes observed in ruminal FA profile had a slight reflect on milk FA profile. Opposite to those changes observed in rumen contents, a diet with CPRC did not reduce proportions of total SFA in milk, probably due to a compensation of the observed lower short chain FA in the rumen with de novo synthesis of these FA in the mammary gland. This is in agreement with the results observed by other authors on sheep milk [6] but differs from the results observed by [5] with sheep and by [57] with dairy cows and with the idea that including long chain UFA in the ration decreases milk short and medium chain FA through inhibition of de novo synthesis in the mammary tissue [58,59]. The abundance of C18:1 cis-9 and PUFA in plant lipids is known to alter the distribution of trans FA in milk fat [60], and in agreement with our results, supplementation with canola or rapeseed has been previously related to the increases in milk trans FA concentrations $[57,61]$. However, other authors have observed no changes [58,62]. This inconsistency could be partially explained by the physical form of the fat supplement. Givens et al. [58] observed that the physical properties of the rapeseed supplement were crucial to observing important changes in the milk FA profile. While rapeseed oil or rapeseed milled increased milk C18:1 isomers (cis and trans), diets containing whole rapeseeds resulted in minor changes, highlighting the key role of the bioavailability of lipids.

Although we observed an increase in ruminal proportions of C18:1 trans-11, which is known as the main precursor of C18:2 cis-9 trans-11 CLA synthesis in mammary tissue, the proportion of these CLA isomer was not increased in the milk of the CPRC group. Pascual et al. [6] also observed no effect of feeding CPRC on milk C18:2 cis-9 trans-11 CLA proportions, but these authors observed a clear increase in the milk C18:1 trans-11 proportions. Moreover, this is in disagreement with previous studies where rapeseedbased feeds increased the milk proportions of C18:2 cis-9 trans-11 CLA and other CLA isomers [57,58,62]. Regarding n3 FA, our results agree with previous studies that have pointed out that supplementing with CPRC, rich in C18:3-n3, increases milk long-chain $n-3$ FAs $[5,6]$.

Finally, regarding production performance, no detrimental effects of using CPRC as a UFA rich lipid source in dairy cow rations was observed, which is consistent with other studies with dairy sheep [5,6] or beef cattle [4]. Moreover, the changes observed in the milk FA profile did not affect the milk sensory quality in a negative manner. In dairy rations, one key factor for the practical use of new feedstuffs, especially those rich in lipids, is to ensure that the final product's taste remains pleasant and free of off-flavors. In the present study, as mentioned, not only was there no negative effect but a better flavor and overall acceptability was observed for milk from CPRC-fed cows compared with the control. Flavor is known as one of the key attributes for acceptability, and among the variables affecting milk flavor, fat is pointed out as one of the most important ones [63], so even slight changes observed in the milk FA profile seemed to be enough to affect milk flavor in a positive way. Other authors have observed no effect of feeding CPRC on sheep curd [6] or cheese [7] sensory properties, whereas the authors of [64] observed similar results in dairy cattle milk when feeding cold-pressed sunflower cake rich in UFA.

This study provided a new insight into the effects of using CPRC as an alternative lipid supplement in dairy cows' diets on ruminal BH of dietary FA and ruminal microbial 
communities and how the changes exerted in the rumen influence productive performance, milk FA profile, and milk sensorial quality.

\section{Conclusions}

In conclusion, a diet with CPRC affected some microbial taxa at the rumen level, modified the fatty acid biohydrogenation process, and resulted in a slight improvement in the milk fatty acid profile and consumer acceptance without detrimental effects on milk production and quality.

Supplementary Materials: The following are available online at https:/ / www.mdpi.com/article/ 10.3390/ani11092553/s1, Table S1: Mean relative abundances of bacterial and Eucaryote phyla in ruminal samples of cows when fed a concentrate formulated with cold-pressed rapeseed cake or a control concentrate, Table S2: Mean relative abundances of bacterial families in ruminal samples of cows when fed a concentrate formulated with cold-pressed rapeseed cake or a control concentrate, Table S3: Mean relative abundances of bacterial genera in ruminal samples of cows when fed a concentrate formulated with cold-pressed rapeseed cake or a control concentrate, Table S4: OTUs at the genus level were significantly different $(\mathrm{q}<0.05)$ between the rumen samples of cows fed the control and concentrate with cold-pressed rapeseed cake.

Author Contributions: Conceptualization, A.G.-R. and I.Z.; methodology, A.G.-R. and I.Z.; formal analysis, I.Z., J.L.L., and I.G.; investigation, I.Z., R.A., A.G.-R., R.R., and N.M.; resources, A.G.-R. and R.R.; data curation, I.Z., R.A., I.G., and J.L.L.; writing-original draft preparation, I.G.; writingreview and editing, A.G.-R., I.Z., R.A., R.R., N.M., H.B., and J.L.L.; supervision, A.G.-R. and R.R.; project administration, A.G.-R. and R.R.; funding acquisition, A.G.-R. and R.R. All authors have read and agreed to the published version of the manuscript.

Funding: This research was funded by INIA RTA2012-00065-C04 and LIFE SEEDCAPITAL-12 $\mathrm{ENV} / \mathrm{ES} / 590$.

Institutional Review Board Statement: All experimental procedures were performed in accordance with the European Union Directive (2010/63/EU) and Spanish Royal Decree (RD 53/2013) for the protection of animals used for experimental and other scientific purposes and were approved by the internal ethics committee (NEIKER-OEBA-2015-011).

Informed Consent Statement: Not applicable.

Data Availability Statement: The datasets generated and/or analyzed during the current study are available from the corresponding author upon reasonable request.

Acknowledgments: The authors thank the staff from Escuela Agraria de Fraisoro (Basque Department of Education) for their assistance during sampling.

Conflicts of Interest: The authors declare no conflict of interest.

\section{References}

1. OECD/FAO. OECD-FAO Agricultural Outlook 2017-2026; OECD Publishing: Paris, France, 2017.

2. Fehlenberg, V.; Baumann, M.; Gasparri, N.; Piquer-Rodríguez, M.; Gavier-Pizarro, G.; Kuemmerle, T. The role of soybean production as an underlying driver of deforestation in the South American Chaco. Glob. Environ. Chang. 2017, 45, 24-35. [CrossRef]

3. Dislich, C.; Keyel, A.C.; Salecker, J.; Kisel, Y.; Meyer, K.M.; Auliya, M.; Barnes, A.D.; Corre, M.D.; Darras, K.; Faust, H.; et al. A review of the ecosystem functions in oilpalm plantations, using forests as a reference system. Biol. Rev. 2017, 92, 1539-1569. [CrossRef]

4. Benhissi, H.; García-Rodríguez, A.; Beltrán de Heredia, I. The effects of rapeseed cake intake during the finishing period on the fatty-acid composition of the longissimus muscle of Limousin steers and changes in meat colour and lipid oxidation during storage. Anim. Prod. Sci. 2020, 60, 1103-1110. [CrossRef]

5. Amores, G.; Virto, M.; Nájera, A.; Mandaluniz, N.; Arranz, J.; Bustamante, M.; Valdivielso, I.; Ruiz de Gordoa, J.C.; GarcíaRodríguez, A.; Barron, L.J.R.; et al. Rapeseed and sunflower oilcake as supplements for dairy sheep: Animal performance and milk fatty acid concentrations. J. Dairy Res. 2014, 81, 410-416. [CrossRef]

6. Pascual, A.; Pineda-Quiroga, C.; Goiri, I.; Atxaerandio, R.; Ruiz, R.; García-Rodríguez, A. Effects of feeding UFA-rich cold-pressed oilseed cakes and sainfoin on dairy ewes' milk fatty acid profile and curd sensory properties. Small Rumin. Res. 2019, 175, 96-103. [CrossRef] 
7. Nájera, A.I.; Bustamante, M.A.; Albisu, M.; Valdivielso, I.; Amores, G.; Mandaluniz, N.; Arranz, J.; Barron, L.J.R.; de Renobales, M. Fatty acids, vitamins and cholesterol content, and sensory properties of cheese made with milk from sheep fed rapeseed oilcake. J. Dairy Sci. 2017, 100, 6962-6971. [CrossRef] [PubMed]

8. Benhissi, H.; García-Rodríguez, A.; Beltrán de Heredia, I. Effect of type and inclusion level of cold-pressed oilseed cakes on in vitro rumen fermentation. Anim. Prod. Sci. 2014, 54, 1709-1713. [CrossRef]

9. Benhissi, H.; Beltrán de Heredia, I.; García-Rodríguez, A. Effect of replacing palm fat with high-linoleic cold-pressed rapeseed or sunflower cakes on fatty acid biohydrogenation in an artificial rumen (Rusitec). Anim. Prod. Sci. 2018, 58, 499-506. [CrossRef]

10. Benhissi, H.; Beltrán de Heredia, I.; García-Rodríguez, A. Apparent nutrient digestibility, nitrogen metabolism and microbial protein synthesis in sheep supplemented with different vegetable fats. Anim. Prod. Sci. 2020, 60, 790-795. [CrossRef]

11. Maia, M.R.; Chaudhary, L.C.; Bestwick, C.S.; Richardson, A.J.; McKain, N.; Larson, T.R.; Graham, I.A.; Wallace, R.J. Toxicity of unsaturated fatty acids to the biohydrogenating ruminal bacterium, Butyrivibrio fibrisolvens. BMC Microbiol. 2010, 18, 10-52. [CrossRef]

12. Timmons, J.S.; Weiss, W.P.; Palmquist, D.L.; Harper, W.J. Relationships among dietary roasted soybeans, milk components, and spontaneous oxidized flavor of milk. J. Dairy Sci. 2001, 84, 2440-2449. [CrossRef]

13. National Research Council. Nutrient Requirements of Dairy Cattle, 7th ed.; The National Academies Press: Washington, DC, USA, 2001. [CrossRef]

14. Association of Official Analytical Chemists (AOAC). Official Methods of Analysis, 18th ed.; AOAC: Gaitherburg, MD, USA, 2007.

15. Van Soest, P.J.; Robertson, J.B.; Lewis, B.A. Methods for dietary fiber, neutral detergent fiber, and nonstarch polysaccharides in relation to animal nutrition. J. Dairy Sci. 1991, 74, 3583-3597. [CrossRef]

16. Robertson, J.B.; Van Soest, P.J. The detergent system of analysis. In The Analysis of Dietary Fibre in Food; James, W.P.T., Theander, O., Eds.; Marcel Dekker: New York, NY, USA, 1981; pp. 123-158.

17. MAPA. Métodos Oficiales del MAPA; BOE 52, 7167; MAPA: Madrid, Spain, 1995.

18. Shingfield, K.J.; Ahvenjärvi, S.; Toivonen, V.; Ärölä, A.; Nurmela, K.; Huhtanen, P.; Griinari, J. Effect of dietary fish oil on biohy-drogenation of fatty acids and milk fatty acid content in cows. Anim. Sci. 2003, 77, 165-179. [CrossRef]

19. Toral, P.G.; Bernard, L.; Belenguer, A.; Rouel, J.; Hervás, G.; Chilliard, Y.; Frutos, P. Comparison of ruminal lipid metabolism in dairy cows and goats fed diets supplemented with starch, plant oil, or fish oil. J. Dairy Sci. 2016, 99, 301-316. [CrossRef]

20. Toral, P.G.; Shingfield, K.J.; Hervás, G.; Toivonen, V.; Frutos, P. Effect of fish oil and sunflower oil on rumen fermentation characteristics and fatty acid composition of digesta in ewes fed a high concentrate diet. J. Dairy Sci. 2010, 93, 4804-4817. [CrossRef]

21. Yu, Z.; Foster, R. Nucleid acid extraction, oligonucleotide probes and PCR methods. In Methods in Gut Microbial Ecology for Ruminants; Makkar, H.P.S., McSweeney, C.S., Eds.; Springer: Dordrecht, The Netherlands, 2005; pp. 81-92.

22. Caporaso, J.G.; Lauber, C.L.; Walters, W.A.; Berg-Lyons, D.; Lozupone, C.A.; Turnbaugh, P.J.; Fierer, N.; Knight, R. Global patterns of 16S rRNA diversity at a depth of millions of sequences per sample. Proc. Natl. Acad. Sci. USA 2011, 108, 4516-4522. [CrossRef] [PubMed]

23. Caporaso, J.G.; Kuczynski, J.; Stombaugh, J.; Bittinger, K.; Bushman, F.D.; Costello, E.K.; Fierer, N.; Peña, A.G.; Goodrich, J.K.; Gordon, J.I.; et al. QIIME allows analysis of high-throughput community sequencing data. Nat. Methods 2010, 7, 335-336. [CrossRef] [PubMed]

24. Edgar, R.C. Search and clustering orders of magnitude faster than BLAST. Bioinformatics 2010, 26, 2460-2461. [CrossRef]

25. McDonald, D.; Price, M.N.; Goodrich, J.; Nawrocki, E.P.; DeSantis, T.Z.; Probst, A.; Andersen, G.L.; Knight, R.; Hugenholtz, P. An improved Greengenes taxonomy with explicit ranks for ecological and evolutionary analyses of bacteria and archaea. ISME J. 2012, 6, 610-618. [CrossRef]

26. Quast, C.; Pruesse, E.; Yilmaz, P.; Gerken, J.; Schweer, T.; Yarza, P.; Peplies, J.; Glöckner, F.O. The SILVA ribosomal RNA gene database project: Improved data processing and web-based tools. Nucleic Acids Res. 2013, 41, D590-D596. [CrossRef]

27. International Organization for Standarization (ISO). Milk and Milk Products_Extraction Methods for Lipids and Liposoluble Compounds; IDF 172 2001; ISO 14156; ISO: Geneva, Switzerland, 2001.

28. International Organization for Standarization (ISO). Milk Fat_Preparation of Fatty Acid Methyl Esters; IDF 182 2002; ISO 15884; ISO: Geneva, Switzerland, 2002.

29. International Organization for Standarization (ISO). Milk Fat_-Determination of the Fatty Acid Composition by Gas-Liquid Chromatography; IDF 184 2002; ISO 15885; ISO: Geneva, Switzerland, 2002.

30. Kramer, J.K.; Cruz-Hernandez, C.; Deng, Z.; Zhou, J.; Jahreis, G.; Dugan, M.E. Analysis of conjugated linoleic acid and trans 18:1 isomers in synthetic and animal products. Am. J. Clin. Nutr. 2004, 79, 1137-1145. [CrossRef]

31. SAS. Enterprise's Guide; SAS Institute Inc.: Cary, NC, USA, 2017.

32. Love, M.I.; Huber, W.; Anders, S. Moderated estimation of fold change and dispersion for RNA-seq data with DESeq2. Genome Biol. 2014, 15, 550. [CrossRef]

33. Le Cao, K.-A.; Rohart, F.; Gonzalez, I.; Dejean, S.; Gautier, B.; Bartolo, F.; Monget, P.; Coquery, J.; Yao, F.Z.; Liquet, B. Mixomics: Omics Data Integration Project. R Package Version 6.1.1. 2016. Available online: https://CRAN.R-project.org/package=mixOmics (accessed on 6 May 2021).

34. R Core Team. R: A Language and Environment for Statistical Computing; R Foundation for Statistical Computing: Vienna, Austria, 2018. Available online: http:/ / www.R-project.org/ (accessed on 6 May 2021). 
35. McKain, N.; Shingfield, K.J.; Wallace, R. Metabolism of conjugated linoleic acids and 18: 1 fatty acids by ruminal bacteria: Products and mechanisms. Microbiology 2010, 156, 579-588. [CrossRef]

36. Zubiria, I.; Garcia-Rodriguez, A.; Atxaerandio, R.; Ruiz, R.; Benhissi, H.; Mandaluniz, N.; Lavín, J.L.; Abecia, L.; Goiri, I. Effect of feeding cold-pressed sunflower cake on ruminal fermentation, lipid metabolism and bacterial community in dairy cows. Animals 2019, 9, 755. [CrossRef]

37. Jenkins, T.C.; Wallace, R.J.; Moate, P.J.; Mosley, E.E. Board-invited review: Recent advances in biohydrogenation of unsaturated fatty acids within the rumen microbial ecosystem. J. Anim. Sci. 2008, 86, 397-412. [CrossRef]

38. Shingfield, K.J.; Lee, M.R.F.; Humphries, D.J.; Scollan, N.D.; Toivonen, V.; Beever, D.E.; Reynolds, C.K. Effect of linseed oil and fish oil alone or as an equal mixture on ruminal fatty acid metabolism in growing steers fed maize silage-based diets. J. Anim. Sci. 2011, 89, 3728-3741. [CrossRef] [PubMed]

39. Glasser, F.; Schmidely, P.; Sauvant, D.; Doreau, M. Digestion of fatty acids in ruminants: A meta-analysis of flows and variation factors: 2. C18 fatty acids. Animal 2008, 2, 691-704. [CrossRef] [PubMed]

40. Bessa, R.J.B.; Alves, S.P.; Jerónimo, E.; Alfaia, C.M.; Prates, J.A.M.; Santos-Silva, J. Effect of lipid supplements on ruminal biohydrogenation intermediates and muscle fatty acids in lambs. Eur. J. Lipid Sci. Technol. 2007, 109, 868-878. [CrossRef]

41. Shingfield, K.J.; Bonnet, M.; Scollan, N.D. Recent developments in altering the fatty acid composition of ruminant-derived foods. Animal 2013, 7, 132-162. [CrossRef]

42. Huws, S.A.; Kim, E.J.; Lee, M.R.; Scott, M.B.; Tweed, J.K.; Pinloche, E.; Wallace, R.J.; Scollan, N.D. As yet uncultured bacteria phylogenetically classified as Prevotella, Lachnospiraceae incertae sedis and unclassified Bacteroidales, Clostridiales and Ruminococcaceae may play a predominant role in ruminal biohydrogenation. Environ. Microbiol. 2011, 13, 1500-1512. [CrossRef] [PubMed]

43. Dewanckele, L.; Toral, P.G.; Vlaeminck, B.; Fievez, V. Invited review: Role of rumen biohydrogenation intermediates and rumen microbes in diet-induced milk fat depression: An update. J. Dairy Sci. 2020, 103, 7655-7681. [CrossRef]

44. Kemp, P.; White, R.W.; Lander, D.J. The hydrogenation of unsaturated fatty acids by five bacterial isolates from the sheep rumen, including a new species. Microbiology 1975, 90, 100-114. [CrossRef] [PubMed]

45. Wallace, J.R.; Chaudhary, L.C.; McKain, N.; McEwan, N.R.; Richardson, A.J.; Vercoe, P.E.; Walker, N.D.; Paillard, D. Clostridium proteoclasticum: A ruminal bacterium that forms stearic acid from linoleic acid. FEMS Microbiol. Lett. 2006, 265, 195-201. [CrossRef] [PubMed]

46. Boeckaert, C.; Vlaeminck, B.; Dijkstra, J.; Issa-Zacharia, A.; Van Nespen, T.; Van Straalen, W.; Fievez, V. Effect of dietary starch or micro algae supplementation on rumen fermentation and milk fatty acid composition of dairy cows. J. Dairy Sci. 2008, 91, 4714-4727. [CrossRef] [PubMed]

47. Shingfield, K.J.; Bernard, L.; Leroux, C.; Chilliard, Y. Role of trans fatty acids in the nutritional regulation of mammary lipogenesis in ruminants. Animal 2010, 4, 1140-1166. [CrossRef] [PubMed]

48. Dewanckele, L.; Vlaeminck, B.; Hernandez-Sanabria, E.; Ruiz-González, A.; Debruyne, S.; Jeyanathan, J.; Fievez, V. Rumen biohydrogenation and microbial community changes upon early life supplementation of 22:6n-3 enriched microalgae to goats. Front. Microbiol. 2018, 9, 573. [CrossRef]

49. Bauman, D.E.; Perfield, J.W.; de Veth, M.J.; Lock, A.L. New perspectives on lipid digestion and metabolism in ruminants. In Proceedings of the Cornell Nutrition Conference, The Cornell University, New York, NY, USA, 21-23 October 2013; pp. 175-189.

50. Lourenço, M.; Ramos-Morales, E.; Wallace, R.J. The role of microbes in rumen lipolysis and biohydrogenation and their manipulation. Animal 2010, 4, 1008-1023. [CrossRef]

51. Buccioni, A.; Decandia, M.; Minieri, S.; Molle, G.; Cabiddu, A. Lipid metabolism in the rumen: New insights on lipolysis and biohydrogenation with an emphasis on the role of endogenous plant factors. Anim. Feed Sci. Technol. 2012, 174, 1-25. [CrossRef]

52. Viviani, R. Metabolism of long-chain fatty acids in the rumen. In Advances in Lipid Research; Paoletti, R., Kritchevsky, D., Eds.; Elsevier: Amsterdam, The Netherlands, 1970; Volume 8, pp. 267-346. [CrossRef]

53. Yáñez-Ruiz, D.; Scollan, N.; Merry, R.; Newbold, C. Contribution of rumen protozoa to duodenal flow of nitrogen, conjugated linoleic acid and vaccenic acid in steers fed silages differing in their water-soluble carbohydrate content. Br. J. Nutr. 2006, 96, 861-869. [CrossRef]

54. Váradyová, Z.; Kišidayová, S.; Siroka, P.; Jalč, D. Comparison of fatty acid composition of bacterial and protozoal fractions in rumen fluid of sheep fed diet supplemented with sunflower, rapeseed and linseed oils. Anim. Feed Sci. Technol. 2008, 144, 44-54. [CrossRef]

55. Majewska, M.P.; Miltko, R.; Belzecki, G.; Skomial, J.; Kowalik, B. Supplementation of rapeseed and linseed oils to sheep rations: Effects on ruminal fermentation characteristics and protozoal populations. Czech J. Anim. Sci. 2017, 62, 527-538. [CrossRef]

56. Newbold, C.J.; de la Fuente, G.; Belanche, A.; Ramos-Morales, E.; McEwan, N.R. The role of ciliate protozoa in the rumen. Front. Microbiol. 2015, 6, 1313. [CrossRef] [PubMed]

57. Hristov, A.N.; Domitrovich, C.; Wachter, A.; Cassidy, T.; Lee, C.; Shingfield, K.J.; Kairenius, P.; Davis, J.; Brown, J. Effect of replacing solvent-extracted canola meal with high-oil traditional canola, high-oleic acid canola, or high-erucic acid rapeseed meals on rumen fermentation, digestibility, milk production, and milk fatty acid composition in lactating dairy cows. J. Dairy Sci. 2011, 94, 4057-4074. [CrossRef] 
58. Givens, I.; Kliem, K.E.; Humphries, D.J.; Shingfield, K.J.; Morgan, V. Effect of replacing calcium salts of palm oil distillate with rapeseed oil, milled or whole rapeseeds on milk fatty-acid composition in cows fed maize silage-based diets. Animal 2009, 3, 1067-1074. [CrossRef]

59. Doreau, M.; Chillard, Y.; Rulquin, H.; Demeyer, D.L. Manipulation of milk fat in dairy cows. In Recent Advances in Animal Nutrition; Garnsworthy, P.C., Wiseman, J., Eds.; Nottingham University Press: Nottingham, UK, 1999; pp. 81-109.

60. Shingfield, K.J.; Chilliard, Y.; Toivonen, V.; Kairenius, P.; Givens, D.I. Trans fatty acids and bioactive lipids in ruminant milk. Adv. Exp. Med. Biol. 2008, 606, 3-65. [CrossRef] [PubMed]

61. Loor, J.J.; Herbein, J.H.; Jenkins, T.C. Nutrient digestion, biohydrogenation, and fatty acid profiles in blood plasma and milk fat from lactating Holstein cows fed canola oil or canolamide. Anim. Feed Sci. Technol. 2002, 97, 65-82. [CrossRef]

62. Rego, O.A.; Alves, S.P.; Antunes, L.M.S.; Rosa, H.J.D.; Alfaia, C.F.M.; Prates, J.A.M.; Cabrita, A.R.J.; Fonseca, A.J.M.; Bessa, R.J.B. Rumen biohydrogenation-derived fatty acids in milk fat from grazing dairy cows supplemented with rapeseed, sunflower, or linseed oils. J. Dairy Sci. 2009, 92, 4530-4540. [CrossRef]

63. Whetstine, C.; Drake, M.A. Flavor characteristics of goat milk and other minor species milk products. In Handbook of Milk of Non-Bovine Mammals; Park, Y.W., Haenlein, G.F.W., Eds.; Blackwell Publishing Professional: Ames, IA, USA, 2006; pp. 107-120.

64. Goiri, I.; Zubiria, I.; Benhissi, H.; Atxaerandio, R.; Ruiz, R.; Mandaluniz, N.; Garcia-Rodriguez, A. Use of cold-pressed sunflower cake in the concentrate as a low-input local strategy to modify the milk fatty acid profile of dairy cows. Animals $2019,9,803$. [CrossRef] [PubMed] 